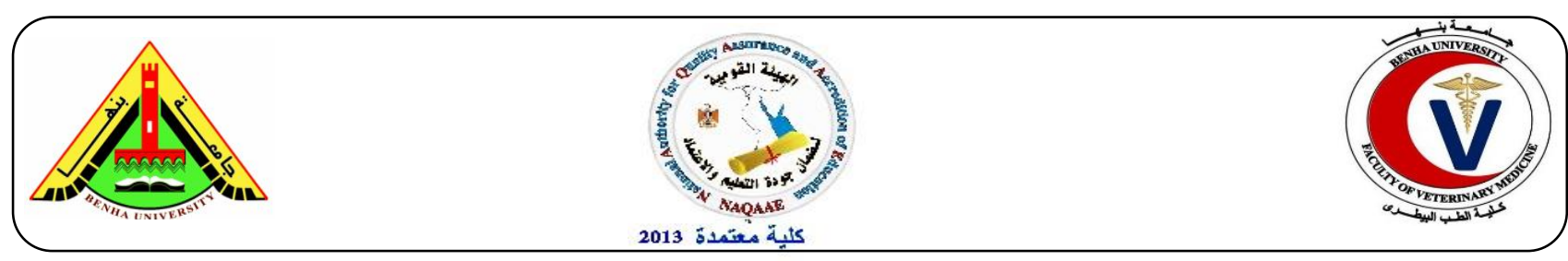

\title{
Pathological Studies on Foot and Mouth disease at Kaluobia Governorate
}

\author{
Mahmoud S. A. Gab-Allah, Abdel-Baset I. El-Mashad, Shawky A. Moustafa and Ibrahim A. \\ El-maghraby
}

Pathology department, Faculty of Veterinary Medicine, Benha University, Egypt

\begin{abstract}
A B S T R A C T
The aim of this study was to detect the pathological affections in various body organs in dead animals by foot and mouth disease (FMD) throughout Kaluobia Governorate, Egypt. The study included 882 clinically affected animals showing characteristic signs of foot and mouth disease including, 827 cattle, and 55 buffalo. The age of the examined animals ranged from 30 days to 3 years and they were of both sexes. The total mortality rates were $6.65 \%$ in cattle and $54 \%$ in buffalos. The most common clinical signs that appeared on examined cases represented by fever, depression, recumbency, lameness, ropy salivation, ptyalism with protrusion of the tongue. Moreover, in young calf's sudden death was the only observed clinical signs. Histopathological examination of both young calves (1-2 months old) and aged calves (12-24 months old), revealed extensive inflammatory and necrotic lesions in the myocardium, lung, liver, kidney, spleen and intestine. Viral isolation from tongue epithelium and molecular identification revealed the presence of FMD virus 'type $\mathrm{O}$ '.
\end{abstract}

Keywords: FMD, Pathology, Cattle and buffalos, Kaluobia.

(http://www.bvmj.bu.edu.eg) (BVMJ-34(1): 195-208, 2018)

\section{INTRODUCTION}

Foot and mouth disease (FMD) is a highly contagious, clinically acute, vesicular, notifiable disease of cloven-hoofed animals such as cattle, sheep, goats, pigs and other domestic animals. Additionally, more than 70 wildlife species including elephant were also susceptible (Biswal, et al., 2015). The aetiologic agent for foot and mouth disease is FMDV genus Apthovirus within the Picornaviridae family with seven serotypes $\mathrm{O}$, A, C, Asia 1, and South African Territory 1 (SAT 1), SAT 2 and SAT 3 (Dukpa, et al., 2011).
The disease in cattle is characterized by fever, inappetence and vesicles formation in and around the mouth and on the feet. The resultant pain causes lameness, manifested by foot "flicking", a tucked-up stance and reluctance to stand or walk. Meanwhile in sheep, the only observed signs were lameness. Moreover, the mortality rate in adult animals is generally low, but it may be high in young animals including calves, lambs and piglets due to acute myocarditis which is considered a fatal lesion of FMD usually occurring without developing the characteristic blister lesions noted in adult animals (Alexandersen, et al., 2003). 
FMD is considered one of the enzootic animal diseases in Egypt (Farag, et al., 2005). Three serotypes of FMDV have been detected in Egypt: O, A and SAT-2. Serotype O is the most endemic since 1970 (Samuel, et al., 1990) while serotype A was isolated and identified in 2006 after importation of live animals from Ethiopia (Abed El-Rahman, et al., 2006). The newest serotype is SAT-2, which was detected in 2012 (EL-Shehawy, et al., 2012; Valdazo-González, et al., 2012). The present work aims to evaluate the histopathological changes of the affected body organs in clinically infected died young and adult cattle and buffalos as well as isolate and identify the serotype of FMDV.

\section{MATERIALS AND METHODS 2.1. \\ Animals}

This work was carried out on a total number of 882 clinically affected animals showing characteristic signs of foot and mouth disease including, 827 cattle, and 55 buffalo. The animals were examined from February 2015 till February 2017 at Kaluobia Governorate.

\subsection{Viral isolation and typing Tongue epithelium samples were} collected in a transport medium composed of equal amounts of glycerol and $0.04 \mathrm{M}$ phosphate buffer, $\mathrm{pH}$ 7.2-7.6, with adding antibiotics (penicillin [1000 International Units (IU)], neomycin sulphate [100 IU], polymyxin B sulphate [50 IU], mycostatin [100 IU]). These samples kept frozen till subjected to trials of vial isolation. Tongue epithelium samples were homogenized in a proper volume of tissue culture media with antibiotic, then clarified by centrifugation and filtrated through $0.22 \mathrm{~nm}$ disposable syringe filter and kept until used for inoculation. Isolation of the virus from epithelium suspension on BHK cell line was done according to (OIE, 2009). Typing of FMDV isolates were done by FMD viral antigen ELISA kit (IZSLER: Brescia, Italy).

\subsection{Reverse Transcription-Polymerase Chain} Reaction (RT-PCR) technique

Specimens from the affected organs (tongue, heart, lung, liver, and kidney) were collected in sterile eppendorf tubes and kept frozen at - 70c till used. Viral RNA was extracted using total RNA Purification Kit following the manufacturer protocol (iNtRON Biotechnology, easy-RED ${ }^{\mathrm{TM}}$ Total RNA Extraction Kit) according to (Esghaei, et al., 2012). RT- PCR was performed on collected samples using universal primers and serotype specific primers in Table (1).

\subsection{Histopathology}

Specimens for histopathological studies were obtained from tongue, heart, lung, kidneys, liver, spleen and intestine of dead animals showing signs of foot and mouth disease. The specimens were collected then fixed in $10 \%$ neutral buffered formalin. After proper fixation, the tissue specimens were trimmed, washed in running tap water, dehydrated in different ascending grades of ethyl alcohol, cleared in xylene and embedded in paraffin. The paraffin embedding block were sectioned at $5 \mu \mathrm{m}$ thickness and stained by hematoxylin and eosin (H\&E stain) according to Bancroft, et al. (1996).

\section{RESULTS}

\subsection{Results of viral isolation and typing}

After 2 serial passages of suspected samples on baby hamster kidney cell (BHK). The infected cell cultures showed specific cytopathic effect (CPE) within 24-48hrs post infection characterized by cell rounding, aggregation, clustering, and partial sheet detachments. These CPE were identified by sandwich typing ELISA as FMDV serotype O. 


\subsection{Results of RT-PCR}

The collected tissue samples tested positive to universal primer and the amplification products were identified at the expected positions of 328 bp (Fig.1a). Typing of FMDV positive samples using serotype specific primers for serotype $\mathrm{O}$ indicated that, all FMDV positive samples from investigated animals were of the $\mathrm{O}$ serotype and the amplification products were identified at the expected positions 1301 bp (Fig.1b).

\subsection{Clinical signs:}

The most common clinical signs that appeared on examined cases showing infection by the disease are represented by fever (40-41c), depression, inappetence, recumbency, lameness, ropy salivation, ptyalism with protrution of the tongue (Fig. 1c). Moreover, in young calves (1-2 months old) sudden death was the only observed clinical signs. The mortality rates among the examined animals were outlined in Table (2).

\subsection{Gross pathology:}

The postmortem examination of dead animals revealed vesicles, multiple areas of erosion and ulceration were commonly distributed on the upper surface of the tongue (Fig.1d), gum, dental pad and cheeks. Young calves (1-2 months old), grossly showed congested myocardial blood vessels accompanied with grayish white areas or patches and streaks were observed on the surface of the auricle and dorsal part of ventricle forming the characteristic tiger heart appearance (Fig.1e). Moreover, on postmortem examination of older calves (1224 months old), dark red ecchymotic hemorrhagic areas were mostly noticed on the surface of the auricle and the ventricles (Fig.1d) and in cross section of affected heart of these cases showed multiple grayish white necrotic foci in the myocardial muscle. The lung showed dark red consolidated areas of pneumonia surrounded by pale focal areas of emphysema which were raised above the adjacent surface. The liver and the kidneys were congested. The spleen was congested with small grayish white foci on the surface, while the large intestine showed congestion of the mesenteric blood vessels.

\subsection{Histopathology:}

The microscopical examination of the tongue showed marked vacuolar and hydropic degeneration in the lining epithelium with vesicles formation in the tongue mucosa which may be opened with each other forming bullae of different size and shapes (Fig.2a). Moreover, the sub epithelial tissue was expanded by homogenous eosinophilic material admixed with moderate number of inflammatory cells mainly neutrophil and lymphocyte. Multifocally, the lingual epithelium showed marked coagulative necrosis of their superficial layers and sometimes completes desquamation of the superficial layers of the necrotic epithelium infiltrated by moderate to large numbers of inflammatory cells were also noticed (Fig.2b). The lingual blood vessels in subepithelial connective tissue revealed vasculitis with occasional fibrin thrombi in their lumen (Fig.2c). Hyalinization of the muscular layer of the tongue admixed with small number of macrophages and neutrophils were demonstrated (Fig.2d).

Histopathological examination of the heart of older calves (12-24 months old) showed marked congestion of the myocardial blood vessels with extensive areas of hemorrhage were observed in between the myocardial muscle (Fig.2e). Occasionally, the myocardial muscle showed necrosis of some muscle fiber replaced by aggregates of mixed inflammatory cells mainly macrophages lymphocyte and neutrophils. 
Meanwhile, the histopathological examination of the heart of young calves (12 months old) revealed mild thickening of the pericardium with infiltration of moderate number of mononuclear inflammatory cells admixed with fibrin threads. Moreover, the myocardial muscle showed characteristic zenker's necrosis of the muscle fibers with massive leukocytic cellular infiltration mainly macrophages, lymphocyte and plasma cells replaced large areas of the myocardial muscles (Fig.2f).

The lung showed severe congestion of the peribronchial blood vessels and interalveolar blood capillaries (Fig.3a) with occasional fibrin thrombi in the lumen of the pulmonary blood vessels. The alveoli showed homogenous eosinophilic materials admixed with fibrin threads and mononuclear inflammatory cells in their lumen. Multifocally, the adjacent alveoli revealed alveolar emphysema with rupture of their wall with syncytium formation (Fig.3b).

The liver showed marked congestion of the central vein, portal veins and hepatic sinusoids. Occasionally, coagulative necrosis of the hepatocyte infiltrated by moderate number of inflammatory cells mainly neutrophils, lymphocytes and macrophages (Fig.3c). The portal area showed mild hyperplasia of biliary epithelium and the periductal interstitium was expanded by congested blood capillaries and edema admixed with small number of fibroblasts and mononuclear inflammatory cells (Fig.3d).

The kidneys showed hypersegmentation of the glomerular tuft (Fig.3e). Multifocally, the lining epithelium of proximal and distal convoluted tubules exhibited marked vacuolar and hydropic degeneration with presence of eosinophilic protinacious materials and hyaline cast were also detected in lumen of some renal tubules particularly in renal medulla (Fig.3f).

Microscopically, the spleen showed thickening of the splenic capsule with subcapsular hemorrhages in the red pulp infiltrated by large number of inflammatory cells mainly lymphocytes and macrophages (Fig.4a). Moreover, the white pulp showed moderate lymphoid depletion accompanied by brownish granules of hemosiderin pigment infiltrating the splenic substance (Fig.4b).

The intestine showed marked congestion of the mucosal blood vessels (Fig. 4c) with leukocytic cellular infiltration in lamina propria replacing part of the intestinal villi (Fig.4d).

Table 1: Forward and reverse primers sequence for candidate genes, region, and size of PCR amplicon (bp).

\begin{tabular}{|c|c|c|c|c|c|}
\hline $\begin{array}{l}\text { Primer } \\
\text { name }\end{array}$ & Serotype & $\begin{array}{c}\text { Primer sequence } \\
\quad(15 \text {---- } / 3)\end{array}$ & Region & $\begin{array}{l}\text { Size } \\
\text { (bp) }\end{array}$ & Reference \\
\hline & \multirow{3}{*}{$\begin{array}{r}\text { All } 7 \\
\text { serotypes }\end{array}$} & GCCTGGTCTTTCCAGGT & & \multirow{3}{*}{328} & \multirow{3}{*}{$\begin{array}{l}\text { Reid, et al. } \\
\quad \text { (2000) }\end{array}$} \\
\hline $1 \mathrm{~F}$ & & $\mathrm{CT}$ & 5 UTR & & \\
\hline $1 \mathrm{R}$ & & $\begin{array}{c}\text { CCAGTCCCCTTCTCGAT } \\
\text { C }\end{array}$ & 5' UTR & & \\
\hline $\mathrm{ARS} 4$ & \multirow{3}{*}{$\mathrm{O}$} & ACCAACCTCCTTGATGT & VP3 & \multirow{3}{*}{1301} & \multirow{3}{*}{$\begin{array}{l}\text { Reid, et al } \\
\quad(2000)\end{array}$} \\
\hline & & GGCT & VP3 & & \\
\hline $\begin{array}{c}\text { R- } \\
\text { NK61 }\end{array}$ & & $\begin{array}{c}\text { GACATGTCCTCCTGATC } \\
\text { TG }\end{array}$ & $2 \mathrm{~B}$ & & \\
\hline
\end{tabular}


Table 2: Mortality rates among the examined cattle and buffalos.

\begin{tabular}{ccccccc}
\hline & \multicolumn{3}{c}{ Cattle } & \multicolumn{3}{c}{ Buffalos } \\
\cline { 2 - 7 } age & Diseased & Dead & Mortality (\%) & Diseased & Dead & Mortality (\%) \\
\hline $1-2 \mathrm{~m}$ & 2 & 2 & $100 \%$ & 2 & 2 & $100 \%$ \\
\hline $2-6 \mathrm{~m}$ & 16 & 2 & $12.5 \%$ & 6 & 5 & $83.3 \%$ \\
\hline $6-12 \mathrm{~m}$ & 775 & 50 & $6.45 \%$ & 6 & 4 & $66.6 \%$ \\
\hline $12-24 \mathrm{~m}$ & 30 & 1 & $3.3 \%$ & 30 & 17 & $56.66 \%$ \\
\hline $24-36 \mathrm{~m}$ & 4 & - & - & 11 & 2 & $18.18 \%$ \\
\hline Total & 827 & 55 & $6.65 \%$ & 55 & 30 & $54 \%$
\end{tabular}

Figure 1: RT- PCR, clinical signs and gross lesions of FMD
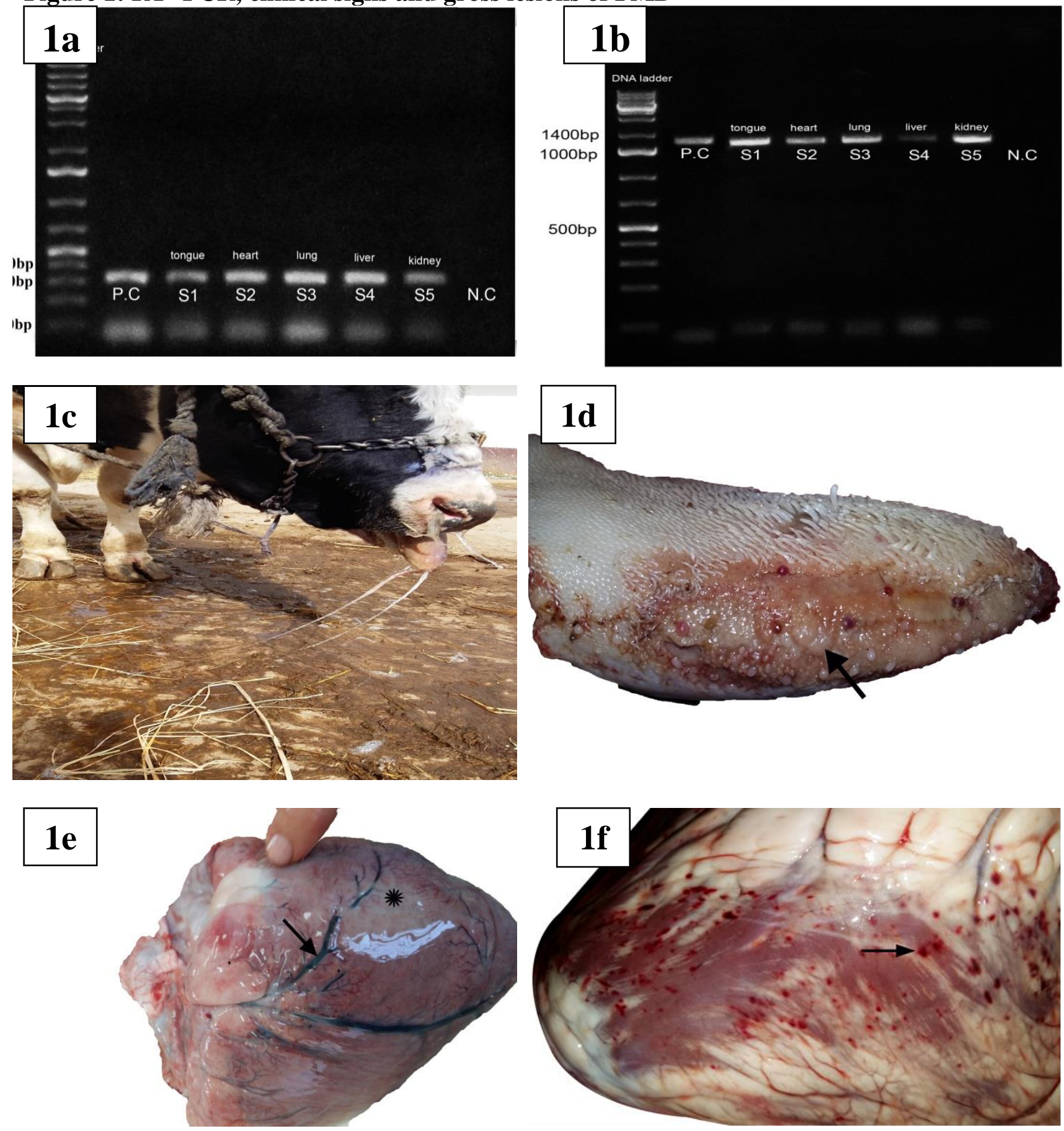
Figure 1: (a)Ethiduim bromide stained agarose gel of RT-PCR using FMD universal primers: lane 1: $100 \mathrm{bp}$ DNA ladder, lane 2: positive control (p.c), lanes: 3-7: positive FMDV isolates ( $328 \mathrm{bp}$ ) from collected samples (S1, tongue; S2, heart; S3, lung; S4, liver; S5, kidney). Lane 8, negative control (N.c). (b) Ethiduim bromide stained agarose gel of RT-PCR using FMD serotype O specific primers: lane 1: $100 \mathrm{bp}$ DNA ladder, lane 2: positive control (p.c), lanes: 3-7: positive FMDV serotype $O$ isolates ( 1301 bp) from collected samples (S1, tongue; S2, heart; S3, lung; S4, liver; S5, kidney). Lane 8, negative control (N.c). (c) Bull of about 2 years age showing ropy salivation, ptyalism, with protrution of the tongue from the mouth. (d) Tongue of dead calves showing vesicles, multiple areas of erosions and ulceration on the upper surface of the tongue (arrow). (e) Heart of dead calves showing congestion in the epicardial and myocardial blood vessels (arrow) accompanied with presence of grayish white areas or patches and streaks on the auricle and dorsal part of ventricle (asterisk). (f) Heart of older calves showing dark red ecchymotic hemorrhagic areas on the surface of the auricle and the ventricles (arrow).

Figure 2: tongue and heart in cattle and buffalos
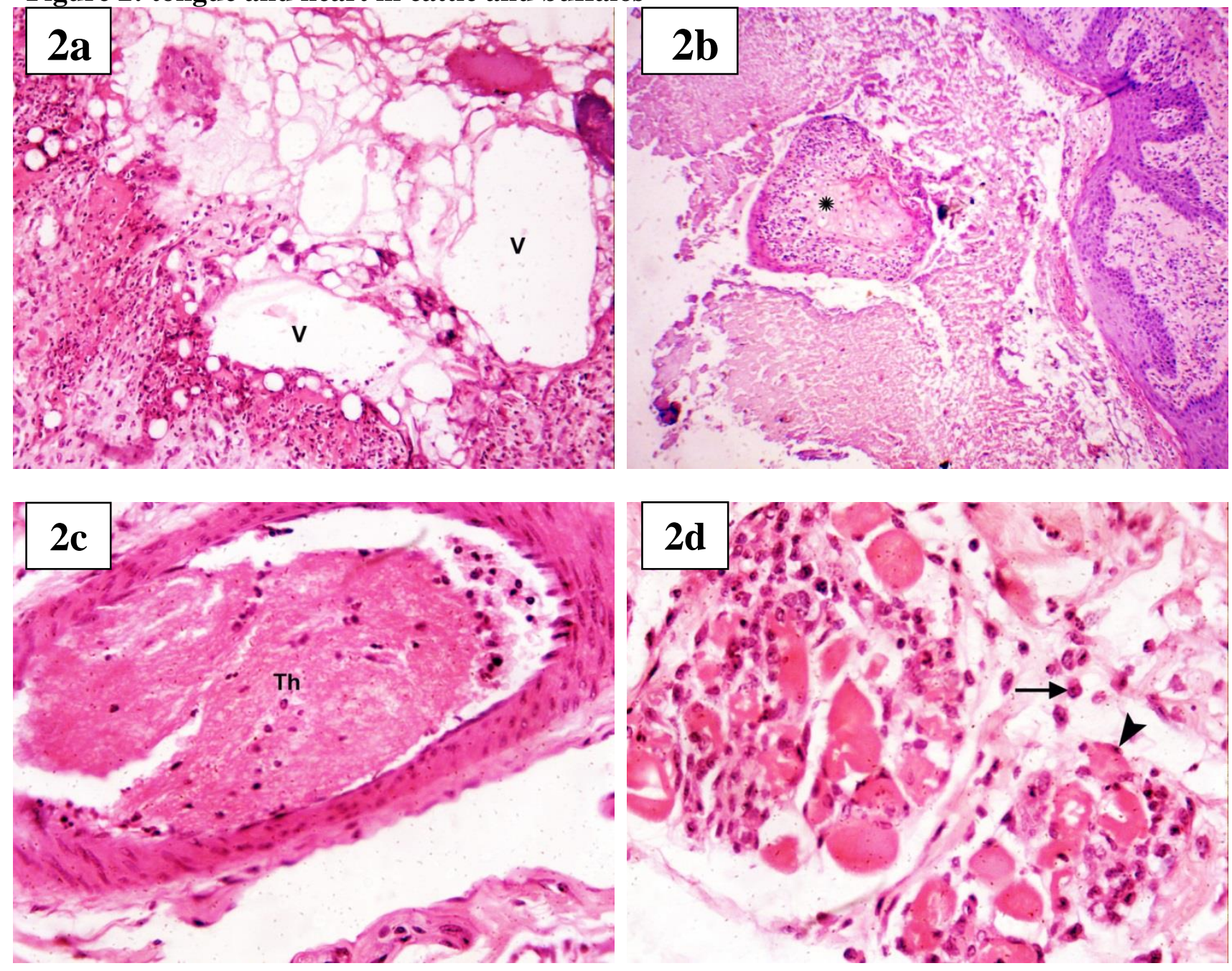
Pathological Studies on Foot and Mouth disease at Kaluobia Governorate

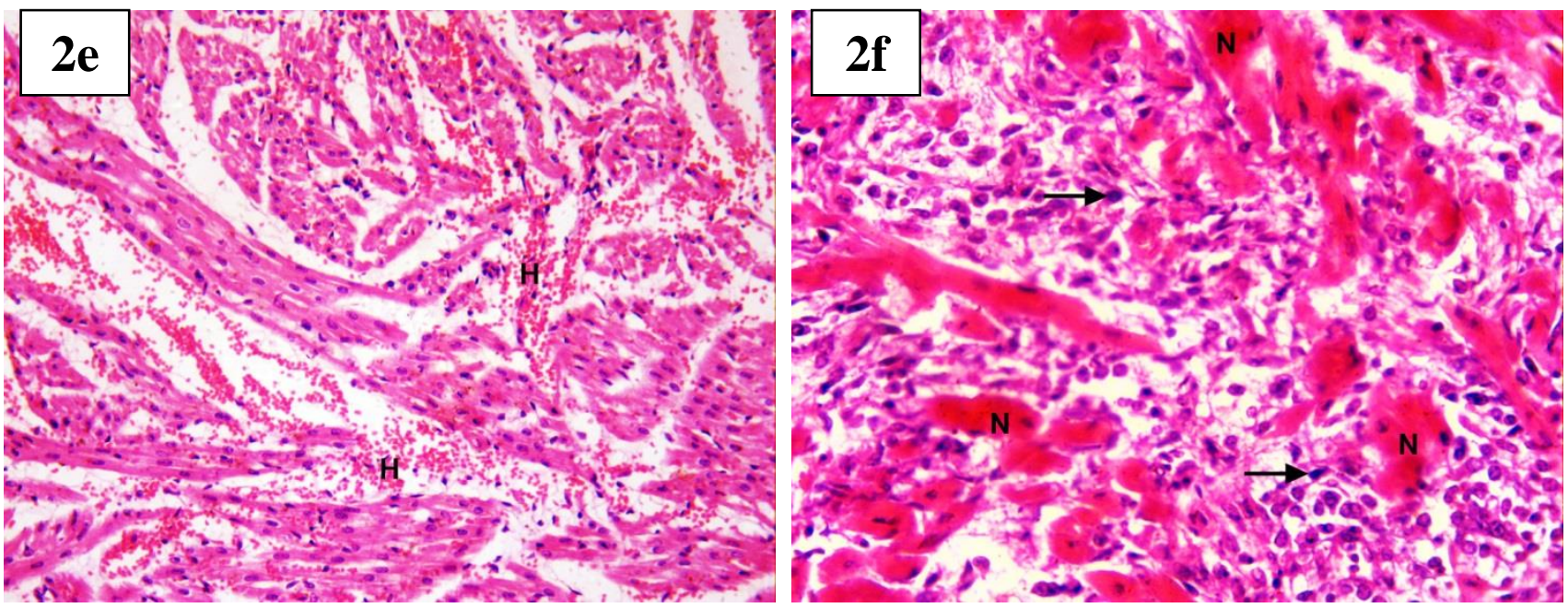

Figure 2: H\&E stained section of tongue ( $a, b, c, d$ ) and heart (e, f) taken from dead animals infected with FMD, showing: (a) Marked vacuolar and hydropic degeneration in epithelium of tongue with vesicles $(\mathrm{V})$ formation which may be opened with each other forming bullae of different size and shapes. (x 100). (b) Coagulative necrosis of their superficial layers and sometimes completes desquamation of the superficial layers of the necrotic epithelium infiltrated by moderate or large numbers of inflammatory cells. (asterisk, x 100). (c) Vasculitis with occasional fibrin thrombi (Th) in the lumen of the lingual blood vessels. (x 400). (d) Hyalinization of tongue muscle fibers characterized by hypereosinophilic sarcoplasm with pyknosis (arrow head) and karyorrhexis of the nuclei and infiltrated by small number of macrophages and neutrophils (arrow). (x 400). (e) Extensive areas of hemorrhage $(\mathrm{H})$ in between the cardiac muscle. (x 100). (f) Zenkers necrosis $(\mathrm{N})$ of the muscle fibers with massive leukocytic cellular infiltration (arrow) mainly macrophages, lymphocyte and plasma cells replaced large areas of the myocardial muscles. (x 200).

Figure 3: lung, liver and kidney in cattle and buffalos
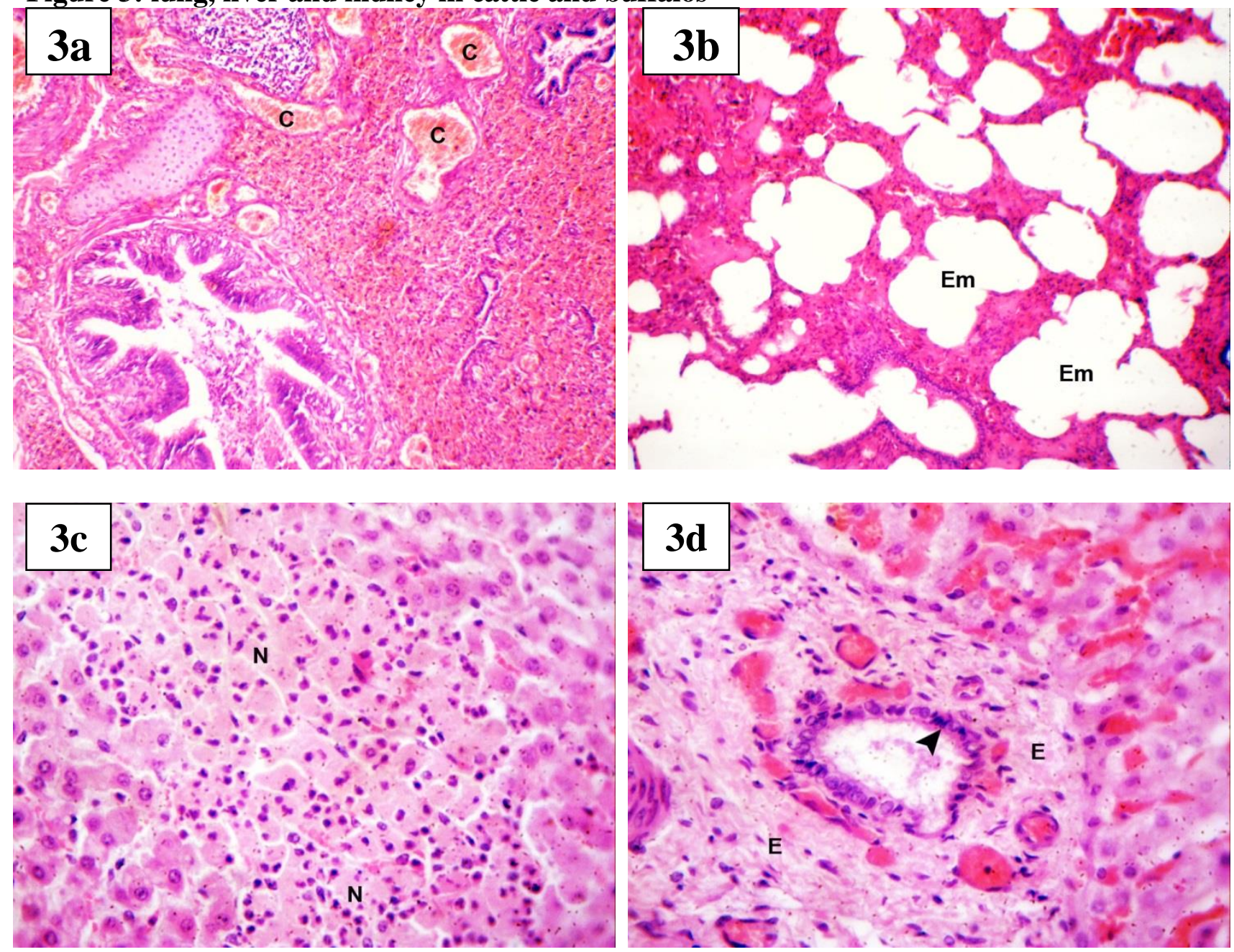

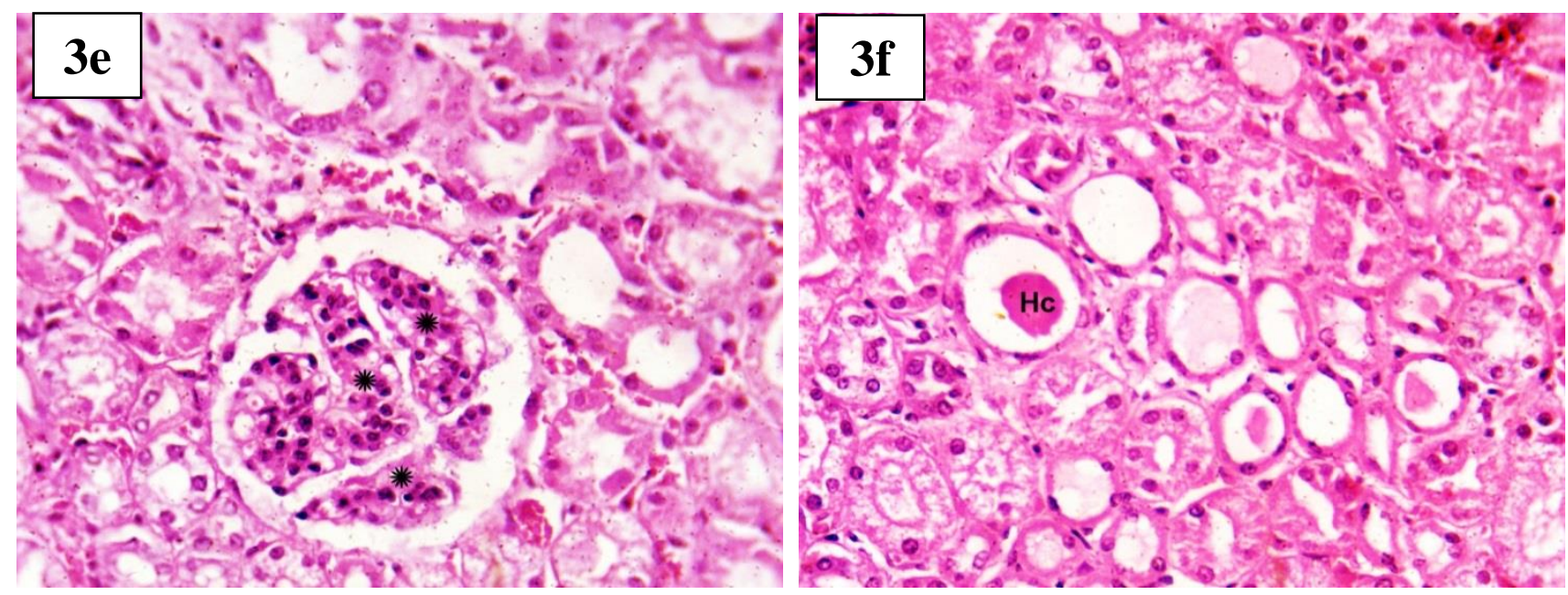

Figure 3: H\&E stained section of lung ( $a, b)$, liver (c, d), kidney (e, f) taken from dead animals infected with FMD, showing: (a) Congestion $(\mathrm{C})$ of the peribronchial blood vessels and inter alveolar blood capillaries. (x 100). (b) Alveolar emphysema (Em) with rupture of their wall with syncytium formation. (x 100). (c) Coagulative necrosis $(\mathrm{N})$ of the hepatocyte infiltrated by moderate number of inflammatory cells mainly neutrophils, lymphocytes and macrophages. (x 400). (d) Mild hyperplasia of biliary epithelium (arrow head) and the periductalinterstitium was expanded by congested blood capillaries and edema (E) admixed with small number of fibroblasts and mononuclear inflammatory cells. (x 400). (e) Hypersegmentation of the glomerular tuft. (asterisk, x 400). (f) Marked vacuolar and hydroic degeneration in the lining epithelium of proximal and distal convoluted tubules with presence of eosinophilicprotinacious materials and hyaline cast (HC) in the lumen of some renal tubules particularly in renal medulla. (x 400).

Figure 4: spleen and intestine in cattle and buffalos
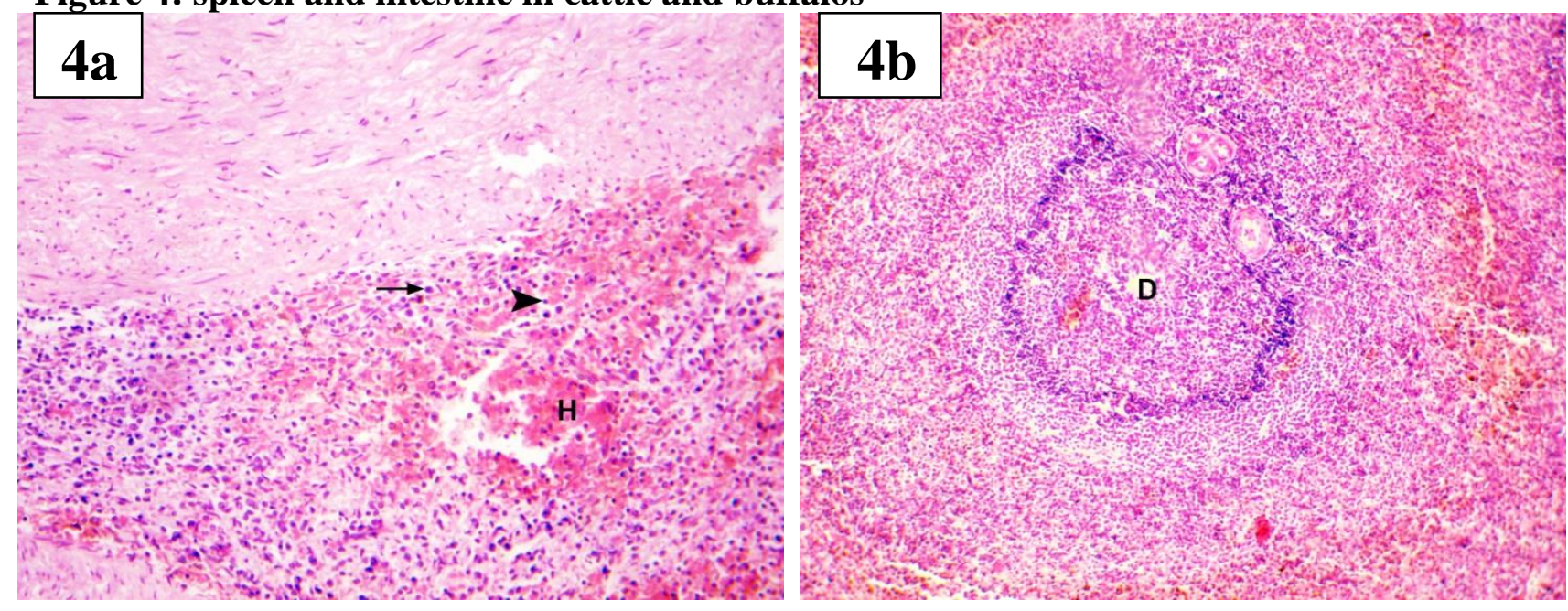

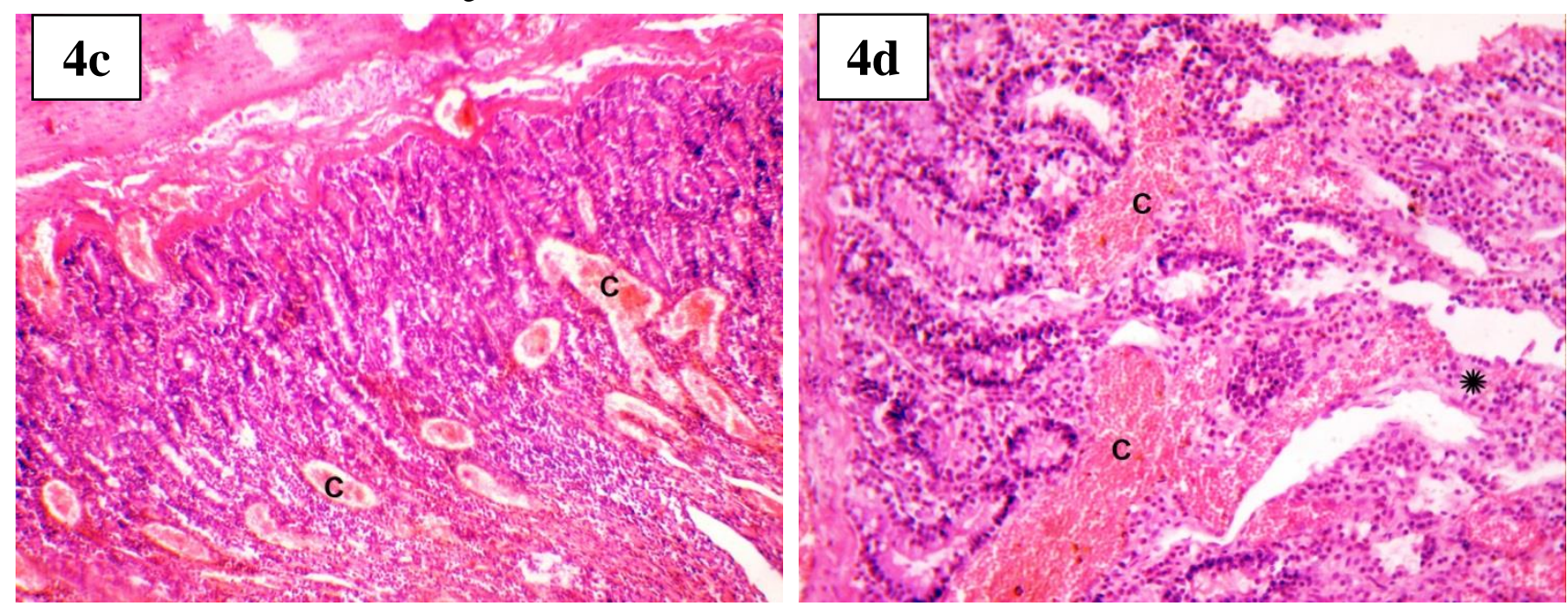

Figure 4: H\&E stained section of spleen $(a, b)$, intestine (c, d) taken from dead animals infected with FMD, showing: (a) Thickening of the splenic capsule with subcapsular hemorrhages $(\mathrm{H})$ in the red pulp infiltrated by large number of inflammatory cells mainly lymphocytes (arrow head) and macrophages (arrow). (x 200). (b) Moderate lymphoid depletion (D) in the white pulp accompanied by brownish granules of hemosiderin pigment infiltrating the splenic substance. (x 200). (c) Marked congestion (C) of the mucosal blood vessels. (x 100). (d) Marked congestion (C) of the mucosal blood vessels with leukocytic cellular infiltration in lamina propria replacing part of the intestinal villi (asterisk). (x 200).

\section{DISCUSSION}

In the present study, 882 clinically affected animals with characteristic signs of foot and mouth disease including, 827 cattle, and 55 buffalos were examined from February 2015 till February 2017 at Kaluobia Governorate. This study was performed to evaluate the histopathological changes in different investigated animals.

The results of virus isolation on BHK21 cell line in this study revealed cell rounding, aggregation, clustering, and partial sheet detachments within 24-48hrs post infection. These results completely agreed with Ibrahim, et al. (2014).

The results of RT-PCR revealed FMD virus serotype $\mathrm{O}$ in the examined sample which has been responsible for many recent outbreaks in Egypt as reported by Ibrahim, et al. (2014) and also by Aidaros, et al. (2016) who found that the most prevalent serotype was $(\mathrm{O})$ in Gharbia and Kaluabiagovernorates during 2014-2015. However, the involvement of other virus strains such as A and SAT2 were previously isolated in Egypt by ElAshmawy, et al. (2013), El-Bayoumy, et al. (2014) and Ali, et al. (2016).

Clinically, the affected cattle and buffalos in this work were suffering from fever, inappetence, anorexia, lameness, marked ptyalism, ropy salivation, and protrusion of tongue, these results completely agreed with El- Ashmawy, et al. (2013), El-Bayoumy, et al. (2014) and Ali, et al. (2016).

In the present study, the most prominent signs in young calves (1-2 months old) represented by sudden death. These results completely agreed with Ali, et al. (2016) and Jubb, et al. (2016). However, Aktas, et al. (2015) recorded fever, tachypnea, tachycardia and arrhythmia in calves less than 2 months of age before death; while with increasing the age of calves the characteristic signs of foot and mouth disease represented by vesicular lesion in feet and mouth were observed. 
Elhaig and Elsheery (2014) recorded diarrhea in some young animals and some others showed a cardiac arrhythmia, followed by difficulty in respiration and grunting, just before death. Meanwhile, buffalo calves less than 1-month old age were found dead without previous clinical signs.

Our results revealed vesicles which commonly distributed on the dorsum of the tongue, gum, dental pad, cheeks. These vesicles may be ruptured leaving multiple areas of erosion and ulceration with inflammed borders. These lesions were characteristic for FMD virus infection in adult cattle as mentioned by Rhyan, et al. (2008) and Jubb, et al. (2016).

In the current research, the most prominent gross lesion in heart of dead calves (1-2 months old) was represented by congestion in the epicardial and myocardial blood vessels accompanied with grayish white areas or patches and streaks on the surface of the auricle and dorsal part of ventricle. Cross section of affected muscle showed grayish white foci or spots in the myocardial muscle giving the characteristic tiger heart appearance. These results completely agreed with Ali, et al. (2016). Meanwhile, the postmortem examination of older calves (1224 months old) in this study revealed presence of dark red ecchymotic hemorrhagic areas on the surface of the auricle and the ventricles; this result totally agreed with Ali, et al. (2016) and also, in cross section of affected heart in this study showed multiple grayish white necrotic foci in the myocardial muscle. Similar results were obtained by ElAshmawy, et al. (2013) who found grayish white small foci of necrosis at the heart base of adult animals and these areas appeared as cooked and pale friable areas.

In this study, the characteristic gross lesions in the lung were represented by dark red consolidated areas of pneumonia surrounded by pale focal areas of emphysema which were raised above the adjacent surface. El-Amir, et al. (2014) and Ali, et al. (2016) found edema and congestion with firm patches on the pulmonary surface.

In this study, the gross lesions in liver were represented by congestion; this result totally agreed with El-Amir, et al. (2014) and Ali, et al. (2016). Meanwhile, gross examination of the kidneys in this work revealed congestion; this result totally agreed with El-Amir, et al. (2014). The gross lesions in the spleen in this work revealed congestion with small grayish white foci on the surface. Similar finding reported by Ali, et al. (2016), who found multifocal irregular grayish white necrotic areas on the splenic surface together with enlargement. Grossly, the intestine in this study showed congestion of the mesenteric blood vessels; this result totally agreed with Ali, et al. (2016).

Microscopically, the tongue mucosa showed marked vacuolar and hydropic degeneration with vesicles formation which may be opened with each other forming bullae of different size and shapes. These results completely agreed with Alexandersen, et al. (2003) and El-Amir, et al. (2014). The lingual epithelium showed coagulative necrosis of their superficial layers with complete desquamation of the necrotic epithelium infiltrated and surrounded by moderate or large number of degenerated and live neutrophils and mononuclear inflammatory cells. These lesions were in complete agreement with Rhyan, et al. (2008) and Ali, et al. (2016). The sub epithelial tissue in this study was expanded by edema admixed with moderate number of inflammatory cells, which are consistent with the findings obtained by Lee, et al. (2009). The muscular layer of the tongue showed hyalinization of some muscle fibers infiltrated by small number of 
macrophages and neutrophils. Moreover, the lingual blood vessels in subepithelial connective tissue revealed vasculitis with occasional fibrin thrombi in their lumen, these results were in partial agreement with Oem, et al. (2008) who found hypertrophy in the lining epithelium of the dermal blood vessels.

Histopathological examination of the heart of older calves (12-24 months old) in this study showed marked congestion of the myocardial blood vessels with extensive areas of hemorrhage were observed in between the myocardial muscle. Occasionally, the myocardial muscle showed necrosis of some muscle fiber replaced by aggregates of mixed inflammatory cells mainly macrophages lymphocyte and neutrophils. These results were in complete agreement with El- Ashmawy, et al. (2013) and Ali, et al. (2016). Previous study (ElAshmawy, et al., 2013) recorded higher level of creatine phosphokinase (CPK) which is an indicator of myocardial degeneration and that suggested the mortality cases in adult animals during 2012 outbreak due to the degenerative effect of FMD SAT2 on the myocardium.

Histopathological examination of the heart of young calves (1-2 months old) revealed mild thickening of the pericardium with infiltration of moderate number of mononuclear inflammatory cells admixed with fibrin threads. These lesions were in partial agreement with Ali, et al. (2016) who found pericarditis in the heart of adult cattle. The myocardial muscle showed characteristic zenker's necrosis of the muscle fibers with massive leukocytic cellular infiltration mainly macrophages, lymphocyte and plasma cells replaced large areas of the myocardial muscles. These lesions were in complete agreement with those previously reported by Alexandersen, et al. (2003), ElAshmawy, et al. (2013) and Ali, et al.
(2016).The fatal outcome of FMD virus in young calves could be attributed to higher level of serum cardiac troponins especially cardiac troponin-I (cTnI) than the values obtained from the non-myocarditis and healthy calves in association with higher affinity of the FMD virus to the developing heart muscle cells resulting in sudden death before vesicular lesions occur on the feet, hooves or mouth (Aktas, et al., 2015).

The lung in this work showed severe congestion of the peribronchial blood vessels and interalveolar blood capillaries with occasional fibrin thrombi in the lumen of the pulmonary blood vessels. The alveoli showed edema, mononuclear inflammatory cells in their lumen with emphysema. These results were in complete agreement with Ali, et al. (2016).

In this study, the liver showed marked congestion of the central vein, portal veins and hepatic sinusoids. Occasionally, coagulative necrosis of the hepatocyte infiltrated by moderate number of inflammatory cells mainly neutrophils, lymphocytes and macrophages were detected. Additionally, the portal area showed mild hyperplasia of biliary epithelium and the periductal interstitium was expanded by congested blood capillaries and edema admixed with small number of fibroblasts and mononuclear inflammatory cells. These results were in a complete agreement with Ali, et al. (2016) who recorded thickening of the hepatic capsule in addition to degenerative changes of hepatic cells as well as infiltration of the portal areas by lymphocytes and macrophages with fibrosis; also, these results were in a partial agreement with El-Amir, et al. (2014), who found focal area of necrosis of hepatocyte with presence of clostridial bacilli within the necrotic areas which indicate secondary bacterial infection. 
In the present work, the kidneys showed hypersegmentation of the glomerular tuft while the renal tubules showed degenerative changes of their lining epithelium associated with interstitial leukocytes and hyaline cast in their lumen. These results were in a complete agreement with El-Amir, et al. (2014) who found severe congestion of renal blood vessels together with necrosis of renal tubular epithelium and glomerular necrosis. Furthermore, the spleen in this study showed thickening of the splenic capsule with subcapsular hemorrhages in the red pulp. Moreover, the white pulp showed moderate lymphoid depletion accompanied by brownish granules of hemosiderin pigment infiltrating the splenic substance. These results were in partial agreement with Patchimasiri and Rodtian (2016) who found only slight lymphoid depletion in the examined spleen. The intestine in this study revealed marked congestion of the mucosal blood vessels with leukocytic cellular infiltration in lamina propria replacing part of the intestinal villi. These results were in a complete agreement with Ali, et al. (2016).

\section{CONCLUSION:}

The present study highlights the importance of FMD as a viral disease causing high mortality and morbidity all over the year, especially in young calves, and this work gives brief description on the associated pathological lesions in non-traditional organs as lung, liver, kidney, spleen and intestine. It seems that myocardial necrosis is the cause of death in young calves. Meanwhile, in adult animals, the cause of death may be due to systemic pathological lesions beside few cardiac lesions observed in these animals.

\section{REFERENCES:}

Abd EL- Rahman, A. O.; Farag, M. A.; Samira EL-Kilany; Eman, M. A.; Manal
AboYazed; Zeidan, S. (2006): Isolation and identification of foot and mouth disease virus during an outbreak of 2006 in Egypt. Kafr Sheikh Vet. Med. J., 4: 50-62.

Aidaros, H. A.; Ashoub, M. M. A.; Fakhry, H. M.; El Daous, H. G. A. (2016):Effect of some factors on prevalence of FMDV antigen in both cattle and buffaloes in Egypt. Benha Vet. Med. J., 30: 341-347.

Aktas, M. S.; Ozkanlar, Y.; Oruc, E.; Sozdutmaz, I. and Kirbas, A. (2015): Myocarditis associated with foot-andmouth disease in suckling calves. Vet.Arhiv., 85: 273-282.

Alexandersen, S.; Zhang, Z.; Donaldson, A. I.and Garland, A. J. (2003): The pathogenesis and diagnosis of foot-andmouth disease. J. Comp. Pathol., 129: 136.

Ali, A. A.; Hafez, M. H.; Ahmad, B.; Hasanin, S. A.; Algabri, N.;Sheire, H. A. (2016): Pathological and molecular investigations on foot and mouth virus outbreaks among cattle herds in Dakahlia Governorate, Egypt. Zag. Vet. J., 44: 128-137.

Banchroft, D. J.; Cook, C. H.; Stirling, R. W. and Turner, D. R. (1996): Manual of histopathological techniques and their diagnostic application. ( $3^{\text {rd }}$.ed.) Chuchill Livingston, Edinbur.

Biswal, J. K.; Subramaniam, S.; Ranjan, R.; Sharma, G. K.; Pattnaik, B. (2015): Isolation And characterisation of footand-mouth disease virus from a captive Indian elephant (Elephasmaximus). Indian. J. Vet. Pathol., 39: 376-379.

Dukpa, K.; Robertson, I. D.; Edwards, J. R; Ellis, T. M. (2011): A retrospective 
study on theepidemiology of foot-andmouth disease in Bhutan, Trop. Anim. Health Prod., 43: 495-502.

El-Amir, Y. O.; Hussein, H. A.; Sayed, M. M. and Aamer, A. A. (2014): Clinical,biochemical and pathological findings in buffaloes with foot-andmouth disease. J. Vet. Adv., 4: 668-676.

El-Ashmawy, W. R.; Mousa, S. A.; Ibrahim, E. E. and Korany, R. M.S. (2013): Clinicalstudy on Egyptian cattle affected with recent isolate of foot-andmouth disease virus SAT2/2012. Int. J. Livestock Res., 4: 52-63.

EL-Bayoumy, M. K.; Abdelrahman, K. A.; Allam, A. M.; Farag, T.K.; Abou-Zeina, H. A.A. and Kutkat, M. A. (2014): Molecular characterization of foot-andmouth disease virus Collected from AlFayoum and Beni- Suef Governorates in Egypt. Global Vet., 13: 828-835.

Elhaig, M. M. \&Elsheery, M. N. (2014): Molecular investigation of foot-andmouth diseasevirus in domestic bovids from Gharbia, Egypt. Trop. Anim. Health Prod., 46: 1455-1462.

El-Shehawy, L.; Azab, A. M. H.; Mossad, W.; El-Sayed, E.; Ismail,A.; Deghady, W.(2012): Real time RT-PCR assay for detection of different serotypes of FMDV in Egypt. Vet. World., 5: 73237.

Esghaei, M.; Monavari, S. H.R.; TavassotiKheiri, M.; Shamsi-Shahrabadi, M.;Heydarchi, B.; Farahmand, B.; Saleh, M. and Fotouhi, F., (2012):Expression of the influenza M2 protein in three different eukaryotic cell lines. J. Virol. Methods.,179: 161-165.

Farag, M. A.; Shawky, M.; Daoud, A. M. (2005): Western blot in comparison
With ELISA for detecting antibodies against foot and mouth disease virus. Vet. Med. J., Giza., 53: 949-955.

Ibrahim, M. S.; Ahmed, L. A.; Kasem, S.; Hodhod, A. A. (2014): Molecular study on footand mouth disease virus in Beheira Governorate, Egypt during 2014. Alexandria J.Vet. Sci., 45: 151160.

Jubb, K. V. F.; Kennedy, P. C. and Palmer's, N. (2016): Pathology of domestic animals (Infectious and Parasitic diseases of alimentary tract) $.6^{\text {th }}$ Ed. Vol. 2, Elsevier. Canada. pp: 117-119.

Lee, S. H.; Jong, M. H.; Huang, T. S.; Lin, Y. L.; Wong, M. L.; Liu,C. I. and Chang, T. J. (2009): Pathology and viral distributions of the porcinophilic footand-mouth disease virus strain $(\mathrm{O} /$ Taiwan/97) in experimentally infected pigs. Transbound. Emerg. Dis., 56: 189-201.

Oem, J. K.; Yeh, M. T.; McKenna, T. S.; Hayes, J. R.; Rieder, E.;Giuffre, A. C.; Robida, J.M.; Lee, K. N.; Cho, I. S.; Fang, X.; Joo, Y. S. and Park, J. H. (2008): Pathogenic characteristics of the Korean 2002 isolate of foot-and-mouth disease virus serotype $\mathrm{O}$ in pigs and cattle. J. Comp. Pathol., 138: 204-214.

OIE, (2009): Foot-and-mouth disease. Chapter 2.1.5. Manual of diagnostic tests and vaccinesfor terrestrial animals. pp: 1-29.

Patchimasiri, T.; Rodtian, P. (2016): Using of immunohistochemistry technique fordetection of foot and mouth disease virus (FMDV), type $\mathrm{O}$ in cattle tissues.Thai-Niah. J., 11: 40-58.

Reid, S. M.; Ferris, N. P.; Hutchings, G. H.; Samuel, A. R. andKnowles, N. J. 
(2000):Primary diagnosis of foot-andmouth disease by reverse transcription polymerase chain reaction. J. Virol. Methods., 89: 167-176.

Rhyan, J.; Deng, M.; Wang, H.; Ward, G.; Gidlewski, T.; McCollum, M.; Metwally, $\quad$ S.;McKenna, $\quad$ T.; Wainwright, S.; Ramirez, A.; Mebus, C. and Salman, M. (2008): Foot-andmouth disease in North American bison (Bison bison) and elk (Cervuselaphusnelsoni): susceptibility, intra- and interspecies transmission, clinical signs, and lesions. J. Wildlife. Dis., 44: 269-79.
Samuel, A. R.; Ouldridge, E. J.; Arrowsmith, A. E. M.; Kitching, R.P. \&Knoweles, N. J. (1990): Antigenic analysis of serotype $\mathrm{O}$ foot andmouth disease virus isolates from the Middle East, 1981 to 1988.Vaccine., 8: 390-396.

Valdazo-González, B.; Knowles, N. J.; Hammond, J.; King, D. P.; (2012): Genomesequences of SAT-2 foot-andmouth disease viruses from Egypt and Palestinian autonomous territories (Gaza Strip). J. Virol., 86: 8901-02. 